\title{
Ascending aortic dissection after proximal bypass anastomotic device
}

\author{
Alberto Weber, MD, Reza Tavakoli, MD, Jurg Gruenenfelder, MD, and Michele Genoni, MD, Zurich, Switzerland
}

Aortic dissection is a rare complication of cardiac operations that is associated with surgical maneuvers such as the placement of the proximal anastomosis and carries a high mortality rate. ${ }^{1,2}$ To maintain the quality of care for patients undergoing off-pump coronary artery bypass grafting (OPCAB), a no-touch technique of the ascending aorta is important. If that is not possible, it is important to perform the proximal anastomoses on the aorta with a no-clamp technique. ${ }^{3}$

\section{CLINICAL SUMMARY}

A 79-year-old man with unstable angina (Canadian Cardiovascular Society class IV and New York Heart Association functional class IV) was referred to our center for coronary angiography. The patient's vascular risk factors included nicotine use, dyslipidemia, arterial hypertension, and diabetes. He also had peripheral arterial vascular disease with a known aneurysm of the descending thoracic aorta. In addition, an aortobifemoral graft and a femoropopliteal bypass had been implanted 5 years previously to treat an infrarenal abdominal aneurysm and a persistent claudication (grade IIb). In the preoperative computed tomographic scan, the ascending aorta showed a maximal diameter of $3.9 \mathrm{~cm}$ and arteriosclerotic plaques over the aortic arch. Cardiac catheterization revealed three-vessel disease with severe coronary sclerosis. Preoperative transesophageal echocardiography showed reduced left ventricular function, with an ejection fraction of $25 \%$. The standard EuroSCORE was 11 . The left radial artery and both internal thoracic arteries were prepared. Complete OPCAB revascularization was performed. The quality of the anastomoses was controlled with transient time-flow measurement (MediStim KirOp AS, Oslo, Norway). The left thoracic artery was grafted to the left anterior descending coronary artery. The radial artery was anastomosed sequentially to the diagonal branch and the circumflex artery. The right thoracic artery was completely harvested and grafted as a side branch off the radial artery to the right inferior pulmonary vein. The left thoracic artery was of small caliber and was not considered for $\mathrm{T} / \mathrm{Y}$-graft anastomosis because of mismatch with the radial artery. The radial artery was implanted into the ascending aorta with the Heartstring device (Guidant Corporation, Indianapolis, Ind) after all distal anastomoses were done.

From the Department for Cardiovascular Surgery, University Hospital, Zurich, Switzerland.

Received for publication Dec 4, 2006; accepted for publication Dec 12, 2006

Address for reprints: Alberto Weber, MD, Zurich University Hospital, Cardiovascular Surgery, Raemistrasse 100, 8091 Zurich, Switzerland (E-mail: alberto.weber@usz. ch).

J Thorac Cardiovasc Surg 2008;136:1364-5

0022-5223/\$34.00

Copyright (c) 2008 by The American Association for Thoracic Surgery doi:10.1016/j.jtcvs.2006.12.075
The intraoperative and postoperative courses were uneventful. Postoperative transesophageal echocardiography was unchanged relative to the preoperative examination. Eight days after the operation, the patient was discharged. At discharge, results of routine blood analysis were normal. Blood pressure was $123 / 75 \mathrm{~mm} \mathrm{Hg}$ with amlodipine besylate (INN amlodipine, $5 \mathrm{mg}$ daily), ramipril (2.5 $\mathrm{mg}$ daily), and sotalol hydrochloride (INN sotalol, $\beta$-blockade, $40 \mathrm{mg}$ 3 times daily).

Six months later, the symptom-free patient was referred to our institution as scheduled for a follow-up computed tomographic scan of the aneurysm of the descending aorta, which showed no change relative to the previous one. Surprisingly, the ascending aorta showed a diameter increase as great as $6.6 \mathrm{~cm}$ and a dissection membrane that extended from above the right coronary sinus to the brachiocephalic trunk (Figure $1, A)$. Because of the high risk of spontaneous rupture, surgical repair of the dissection was undertaken in this otherwise symptom-free patient.

Preoperative transesophageal echocardiography showed impaired left ventricular function, with an ejection fraction of $20 \%$ and minimal aortic valve insufficiency. The right subclavian artery and the right femoral vein were cannulated. The entry of the dissection originated from the proximal radial artery anastomosis on the anterior ascending aorta (Figure 1,B) and the neohole on the aorta showed an irregular shape. The ascending aorta was replaced with a 26-mm Dacron polyester fabric graft. The proximal radial artery graft was reimplanted into the graft. Unfortunately, the patient had massive ST elevations develop on the electrocardiogram. Even with maximal inotropic drug support (no intra-aortic balloon pump because of the descending aorta findings), it was not possible to wean the patient from extracorporeal cardiopulmonary circulation, and he died in the operating room.

\section{DISCUSSION}

In a recent study, acute ascending aortic dissection was found to have an incidence of $0.97 \%$ after OPCAB. ${ }^{4}$ This may be due, at least in part, to the fact that in OPCAB aortic side-clamping for construction of the proximal anastomoses is done under normal blood pressure and pulsatile conditions, which may add potential stress to the direct laceration, torsion, or mechanical compression of the ascending aorta.

The method of choice to minimize aortic manipulation is the use of arterial conduits for in situ or T-graft arterial configurations. Furthermore, to avoid this potential complication, efforts have been made to develop mechanical devices that allow construction of the proximal anastomoses without aortic side-clamping. Since the beginning of 2003 , we have exclusively used the Heartstring device to construct all proximal anastomoses on the aorta. With this device, we 

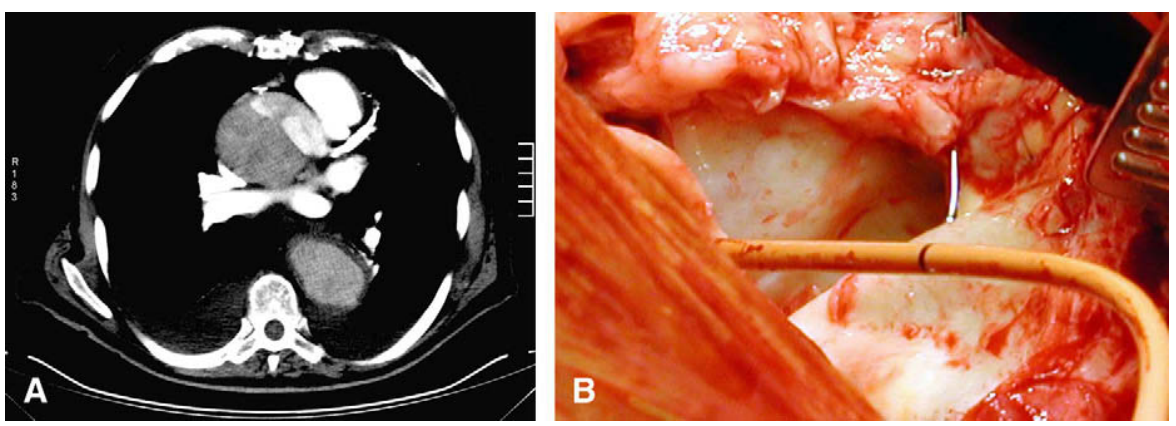

FIGURE 1. A, Aortic dissection with entry arising from proximal bypass anastomosis on 6-month postoperative computed tomographic scan. B, Intraoperative finding; metal probe shows immediate connection between proximal anastomosis of radial artery and entry tear of dissection.

TABLE 1. Neurologic outcomes of patients undergoing off-pump cardiopulmonary bypass grafting with Heartstring* device for construction of the proximal aortic anastomoses

\begin{tabular}{lcc}
\hline & Mar-Dec 2003 & Jan-Dec 2004 \\
\hline No. of patients & 189 & 256 \\
Proximal anastomoses (No.) & 333 & 451 \\
Neurologic events (\%) & $1 \%$ & $0 \%$ \\
\hline
\end{tabular}

*Guidant Corporation, Indianapolis, Ind.

have been able to reduce neurologic complications (Table 1). This device selectively addresses the question of clampless revascularization without adding new problems derived from the anastomosis technique, which seems to be the drawback of several automatic proximal anastomosis devices currently in development. ${ }^{5}$

In conclusion, this report underlines further the need for long-term follow-up of patients in whom new devices for proximal anastomoses are used, to check for the potential development of late aortic dissection. In addition, it emphasizes the importance of identifying predisposing factors that might help in selecting appropriate patients for the application of such devices.

\section{References}

1. Stanger O, Oberwalder P, Dacar D, Knez I, Rigler B. Late dissection of the ascending aorta after previous cardiac surgery: risk, presentation and outcome. Eur J Cardiothorac Surg. 2002;21:453-8.

2. Boruchow IB, Iyengar R, Jude JR. Injury to ascending aorta by partial-occlusion clamp during aorta-coronary bypass. J Thorac Cardiovasc Surg. 1977;73:303-5.

3. Tavakoli R, Reuthebuch O, Hofer C, Grüenenfelder J, Genoni M. Off-pump coronary bypass grafting: the Zurich experience. Heart Surg Forum. 2005;8:E246-8.

4. Chavanon O, Carrier M, Cartier R, Hebert Y, Pellerin M, Page P, et al. Increased incidence of acute ascending aortic dissection with off-pump aortocoronary bypass surgery? Ann Thorac Surg. 2001;71:117-21.

5. Reuthebuch O, Kadner A, Lachat M, Kuenzli A, Schurr U, Turina M. Early bypass occlusion after deployment of nitinol connector devices. $J$ Thorac Cardiovasc Surg. 2004;127:1-6.

\section{Sclerosing hemangioma with an air halo}

Jung-Jyh Hung, MD, ${ }^{\text {a,b,c }}$ Jung-Sen Liu, MD, PhD, ${ }^{\mathrm{b}}$ and Wen-Hu Hsu, MD, ${ }^{\mathrm{c}}$ Taipei, Taiwan

Sclerosing hemangioma (SH), an unusual benign pulmonary neoplasm, was first described by Liebow and Hubbell ${ }^{1}$ in 1956. It occurs predominantly in middle-aged women. ${ }^{2}$ Most patients have no symptoms, with the tumors being de-

\footnotetext{
From the Institute of Clinical Medicine, National Yang-Ming University, ${ }^{\text {a the Depart- }}$ ment of Surgery, Cathay General Hospital, and School of Medicine, Fu Jen Catholic University, ${ }^{b}$ and the Division of Thoracic Surgery, Department of Surgery, Taipei Veterans General Hospital and School of Medicine, National Yang-Ming University, ${ }^{\mathrm{c}}$ Taipei, Taiwan.

Received for publication July 21, 2007; revisions received Aug 24, 2007; accepted for publication Nov 20, 2007

Address for reprints: Wen-Hu Hsu, MD, Division of Thoracic Surgery, Department of Surgery, Taipei Veterans General Hospital, No. 201, Section 2, Shih-Pai Rd, Taipei 112, Taiwan (E-mail: whhsu@vghtpe.gov.tw).

J Thorac Cardiovasc Surg 2008;136:1365-7

$0022-5223 / \$ 34.00$

Copyright (c) 2008 by The American Association for Thoracic Surgery

doi:10.1016/j.jtcvs.2007.11.073
}

tected incidentally during routine chest radiographic examination. Although SH is usually seen as a solitary peripheral nodule less than $3 \mathrm{~cm}$ in diameter, multiple lesions have been reported in as many as $4 \%$ of all cases. ${ }^{2}$ The characteristic radiologic feature of $\mathrm{SH}$ is a well-defined nodule with good enhancement. We present the case of a patient with SH with an unusual air halo.

\section{CLINICAL SUMMARY}

A symptom-free 23-year-old man came to our clinic because of an abnormal shadow found on a chest radiographic film during military physical check-up. He reported unremarkable family and medical histories. Physical examination revealed no abnormal physical findings. Laboratory data were normal, including normal carcinoembryonic antigen 